Proc. Indian Acad. Sci. (Earth Planet. Sci.), Vol. 89, Number 2, July 1980, pp. 137-143.

(C) Printed in India.

\title{
On the growth and decay of irregularities in the ionosphere
}

\author{
HARI OM VATS and M R DESHPANDE \\ Physical Research Laboratory, Ahmedabad 380009, India
}

MS received 27 June 1978; revised 31 October 1979

\begin{abstract}
It has been demonstrated that VHF/UHF scintillation data can be used to evaluate important physical parameters such as scale sizes, strength, growth and decay of irregularities in the equatorial ionosphere. These parameters are important in constructing electroject models. It is shown that large scale irregularities are generated first which later break into smaller scale sizes. During the decay phase, the small scale irregularities disappear first after followed by large scale irregularities. The generation and destruction time of these irregularities has been estimated to be around $20 \mathrm{~min}$. In addition these irregularities affect propagation of radio waves from HF to UHF range which suggests the existence of a wide spectrum of irregularities in the ionosphere. It has been found that the scale sizes of daytime $E$ region irregularities are smaller than those in the $F$-region during night-time. The growth rate of the irregularities seems to be larger in the E-region than in the $F$ region of the ionosphere.
\end{abstract}

Keywords. Equatorial irregularities; scintillation.

\section{Introduction}

Irregular fluctuations or scintillations of amplitude, phase and angle of arrival are occasionally observed on radio signals recorded after propagation through the i onosphere where irregularities might exist. Scintillations have been observed at f requencies ranging from $\mathrm{HF}$ to UHF bands using radio stars, orbiting and geostationary satellites. The irregularities believed to be responsible for scintillations are produced by turbulent processes, plasma instabilities, incoming particle streams, or other physical processes which need to be known if the upper atmosphere is to be understood completely. The present paper reports investigations of scale sizes, strength, growth and decay of ionisation irregularities carried out using amplitude scintillations at 40,140 and $360 \mathrm{MHz}$ from a geostationary satellite ATS-6 recorded at an equatorial station, Ootacamund (sub-ionospheric $\operatorname{dip} 4 \cdot 4^{\circ} \mathrm{N}$ ). These physical parameters could be useful in developing scintillation theories as well as in understanding the formation of irregularities. Much of this information is either meagre or non-existent (Bowles et al 1963; Prakash et al 1971) and hence the current investigations were undertaken. 


\section{Method of analysis}

We selected a few typical cases of normal scintillation records for 40,140 and $360 \mathrm{MHz}$; the word normal emphasises that in all these cases scintillation index $S_{4}$ follows $S_{4} \propto f^{-n}$ law where $f$ is the carrier frequency and exponent $n$ is around 1 . Such scintillation records can be explained by the diffraction theory (Briggs and Parkin 1963). The index $S_{4}$ represents normalised rms power fluctuation of the received signal (Briggs and Parkin 1963) and is given by:

$$
\text { where } \begin{aligned}
S_{4} & =\sqrt{2} \phi_{0}\left[1-\left(\cos u_{1} \cos u_{2}\right)^{1 / 2} \cos \frac{1}{2}\left(u_{1}+u_{2}\right)\right]^{1 / 2}, \\
\phi_{0} & \left.=\left[\pi^{1 / 4} r_{0} \lambda\left\langle(\Delta N)^{2}\right\rangle L a R_{0} \sec i\right)^{1 / 2}\right] / \beta^{1 / 2} \\
\tan u_{1} & =2 \lambda Z / K_{u}^{2} \\
\tan u_{2} & =2 \lambda Z / \beta^{2} K_{0}^{2}, \\
\beta^{2} & =a^{2} \sin ^{2} \psi+\cos ^{2} \psi \\
r_{0} & =\text { classical radius of electron, } \\
\lambda & =\text { wavelength of the carrier wave, } \\
\triangle N & =\text { deviation of ionisation density in the ionosphere, } \\
L & =\text { thickness of the irregular region of the ionosphere, } \\
a & =\text { axial ratio of the irregularities, } \\
i & =\text { zenith angle of the source, } \\
Z & =\text { height of the irregularities above the ground, } \\
\psi & =\text { propagation angle. }
\end{aligned}
$$

$\mathbf{R}_{\mathbf{0}}$ is the scale size which is the measure of the distance at which the correlaticn of ionisation density falls to $1 / e$ in a direction transverse to the magnetic field. This may be called effective scale size of the irregularities for scintillation (henceforth we will use the term 'scale size' for this).

Equation (1) has three unknowns viz. $R_{0},\left\langle(\Delta N)^{2}\right\rangle$ and $L$; of these the latter two appear as a product which therefore cannot be separated. With the experimental values of $S_{4}$ at 40,140 and $360 \mathrm{MHz}$ the above parameters can be evaluated.

Earlier studies of scintillations at low and mid-latitudes have shown that nighttime scintillations are mainly due to spread-F irregularities (Kōster 1972; Mullen 1973; Chandra and Rastogi 1974) and those during day-time are due to Es irregularities (Aarons and Whitney 1968; Rastogi and Iyer 1976). Recent scintillation observations at Ootacamund and ionosonde observations at a nearby station Kodaikanal have shown a one-to-one correspondence of night-time scintillations with either spread- $F$ or night $E s$ irregularities and of day-time scintillations with non Es- $q$ type of irregularities (Rastogi et al 1977 and Chandra et al 1979). Thus for the analysis, the height $Z$ has been assumed as $100 \mathrm{~km}$ for $E$-region irregularities, and $350 \mathrm{~km}$ for $F$-region irregularities. Similar heights have been reported by McClure (1964) using orbiting satellite observations.

Kent and Koster (1966) found that night-time $F$-region irregularities are highly elongated, with axial ratios of the order of $20: 1$, and are aligned along the earth's 
magnetic field lines. Chandra et al (1970) reported that the equatorial ionospheric irregularities are highly anisotropic, suggesting that these irregularities are elongated along the magnetic lines of force, with the axial ratio ranging from 3 to 12 . Recently Deshpande et al (1978) reported a typical value of axial ratio of fieldaligned irregularities in the equatorial ionosphere around 10 . In view of these equatorial observations of the irregularities we have assumed axial ratio $a=2,5$ and 10 for day-time irregularities and 10,20 and 30 for night-time irregularities in our calculations. However, Figures 1 to 3 are for $a=10$ only.

Equation (1) was solved numerically on IBM 360/44 computer. The solutions provide temporal variations of scale size $\left(R_{0}\right)$, and the quantity $\left\langle(\triangle N)^{2}\right\rangle L$. The latter is the product of mean square deviation of ionisation density with respect to ambient ionisation density, and thickness of the ionosphere containing irregularities; it can be regarded as the strength of the irregularities.

\section{Results}

\subsection{Daytime irregularities}

Amplitude records of 40,140 and $360 \mathrm{MHz}$ at Ootacamund were analysed every five minutes to derive scintillation indices $S_{4}$, which were then used in equation (1) to estimate scale size $\mathbf{R}_{\mathbf{0}}$ and irregularity strength $\left\langle(\triangle N)^{2}\right\rangle L$. Figure 1 shows the temporal variations of scintillation index $S_{4}$ at 40,140 and $360 \mathrm{MHz}$, on

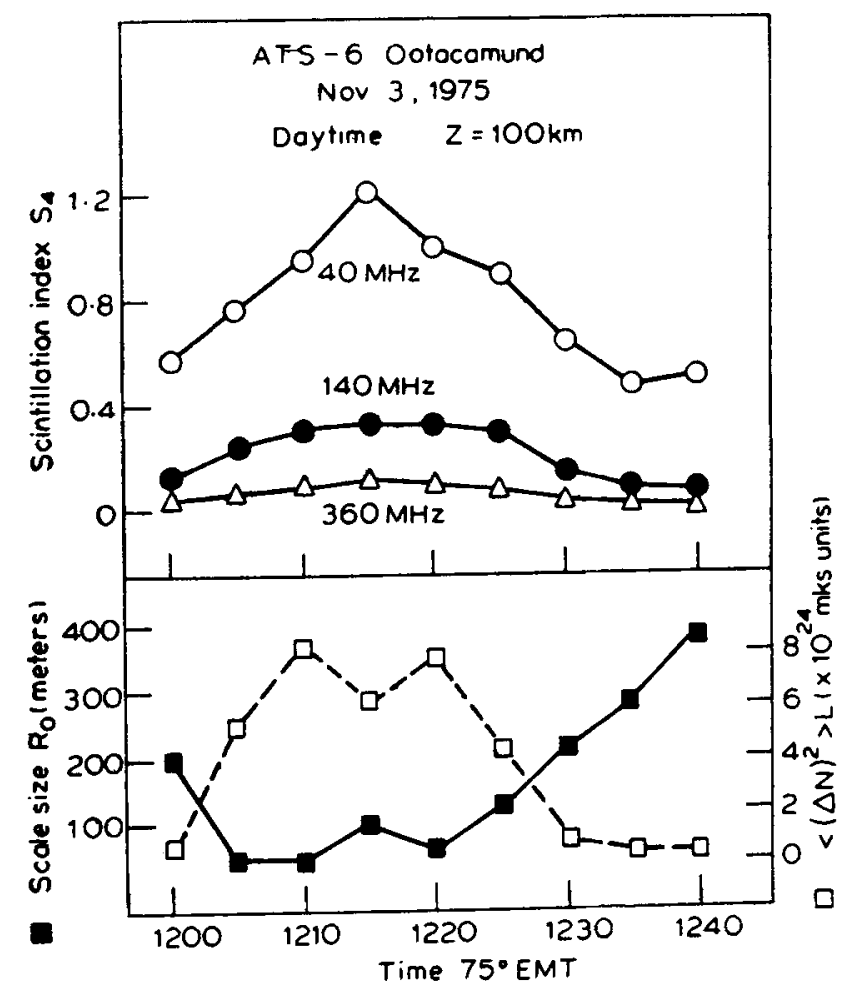

Figure 1. Temporal variation of scintillation indices at 40,140 and $360 \mathrm{MHz}$, scale size $R_{0}$ and strength of irregularity $\left\langle(\triangle N)^{2}\right\rangle L$ for daytime irregularities. 
3 November 1975 between $1200-1240 \mathrm{hr}\left(75^{\circ} \mathrm{EMT}\right)$, and the evaluated parameters scale size $R_{0}$ and irregularity strength $\left\langle(\triangle N)^{2}\right\rangle L$. After $1200 \mathrm{hr} S_{4}$ increases and attains its peak value around $1215 \mathrm{hr}$. During this period, strength of irregularities $\left\langle(\Delta N)^{2}\right\rangle L$ also increases whereas the scale size $R_{0}$ decreases. After $1215 \mathrm{hr}$ scintillation indices at 40,140 and $360 \mathrm{MHz}$ decrease and this decrease is associated with increase of scale size $R_{0}$ and decrease of irregularity strength $\left\langle(\Delta N)^{2}\right\rangle L$. If one assumes a reasonable value for thickness of the jrregular region, then the temporal variation of r.m.s. deviation of ionisation density of the irregularities with respect to the ambient density can be evaluated. Increasing value of ionisation density deviation $(\triangle N)$ would indicate growth rate and decreasing value of that would indicate decay rate. Recently Chandra et al (1979) have reported that the daytime scintillation is associated with non $E s-q$ type of $E$-region irregularities; the non $E s-q$ type irregularities usually occur during counter-electrojet events. Prakash et al (1976) reported the observations of irregularities in the altitude region of $106-112 \mathrm{~km}$ during a counter electrojet. Hence for daytime scintillations one can assume the thickness of irregular region around $6 \mathrm{~km}$. Assuming $L=6 \mathrm{~km}$, the rate of increase of deviation of ionisation density $(\triangle N)$ which we refer to as the growth rate of the irregularities in the line of sight of the ray path from ATS-6 to Ootacamund was calculated. The values thus obtained for $\alpha=2,5$ and 10 are $2 \times 10^{7}, 2.5 \times 10^{7}$ and $2.9 \times 10^{7} \mathrm{el} / \mathrm{m}^{3} / \mathrm{sec}$ respectively. The value of scale size $R_{0}$ ranges from $50-500$ metres in all these cases. The daytime ambient electron density $(N)$ in the $E$-region of the ionosphere around local noon, is of the order of $10^{11} \mathrm{el} / \mathrm{m}^{3}$. Taking this value of ambient electron density, for the irregularities, the ratio $(\triangle N / N)$ was obtained. It ranges from (1) $1-8 \%$; (2) $1-11 \%$ and (3) $1-15 \%$ for $a=2,5$ and 10 respectively. These values agree with early rocket measurements at Thumba (Prakash et al 1971). This agreement conffrms the propriety of the theory used in this paper.

\subsection{Nighttime irregularities}

Similar calculations of the parameters of the nighttime irregularities were carried out assuming $\alpha=10,20$ and 30 . As the nighttime scintillation is most of the time associated with the $F$-region irregularities, the examples of scintillation associate with spread- $F$ were selected. Figures 2 and 3 show the temporal variations of scintillation indices $S_{4}$ at 40,140 and $360 \mathrm{MHz}$, scale size $R_{0}$ and irregularity strength $\left\langle(\triangle N)^{2}\right\rangle L$ on two typial nights viz. 11 and 25 November 1975. Note that these figures are for $a=10$ and $Z=350$. Here again an increase of $S_{4}$ is associated with an increase of $\left\langle(\Delta N)^{2}\right\rangle L$ and decrease of $R_{0}$ and a decrease in $S_{4}$ is associated with a decrease of $\left\langle(\Delta N)^{2}\right\rangle L$ and an increase of $R_{0}$. An important point to be mentioned about figure 3 is that at $0125 \mathrm{hr}$ scintillation index $S_{4}$ at $40 \mathrm{MHz}$ alone increases whereas those at 140 and $360 \mathrm{MHz}$ remain unchanged. During this period, scale size and strength of the irregularity both have increased. Because of increase in scale size of the irregularities, their effect of causing scintilJation on higher frequencies, i.e. 140 and $360 \mathrm{MHz}$ have reduced, while an increase in the strength of the irregularities would increase the scintillation index at $40 \mathrm{MHz}$. Such effects are also known as " filtering effect" of the irregularities. In these cases the scale sizes $R_{0}$ range between $100-1000$ metres and 150-2000 metres respectively. 


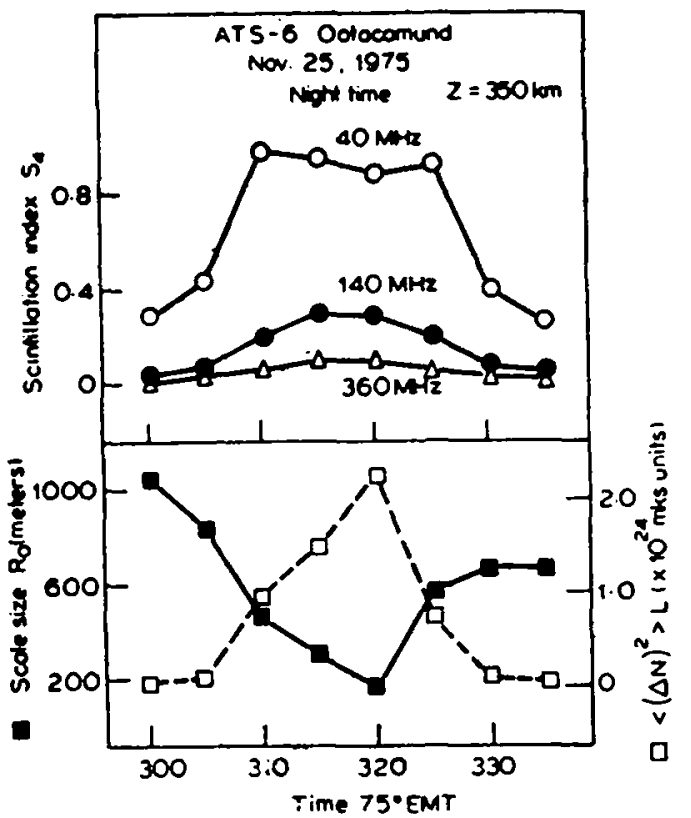

Figure 2. Temporal variation of scintillation indices at 40,140 and $360 \mathrm{MHz}$, scale size $R_{0}$ and strength of irregularity $\left\langle(\Delta N)^{2}\right\rangle L$ for nighttime irregularities.

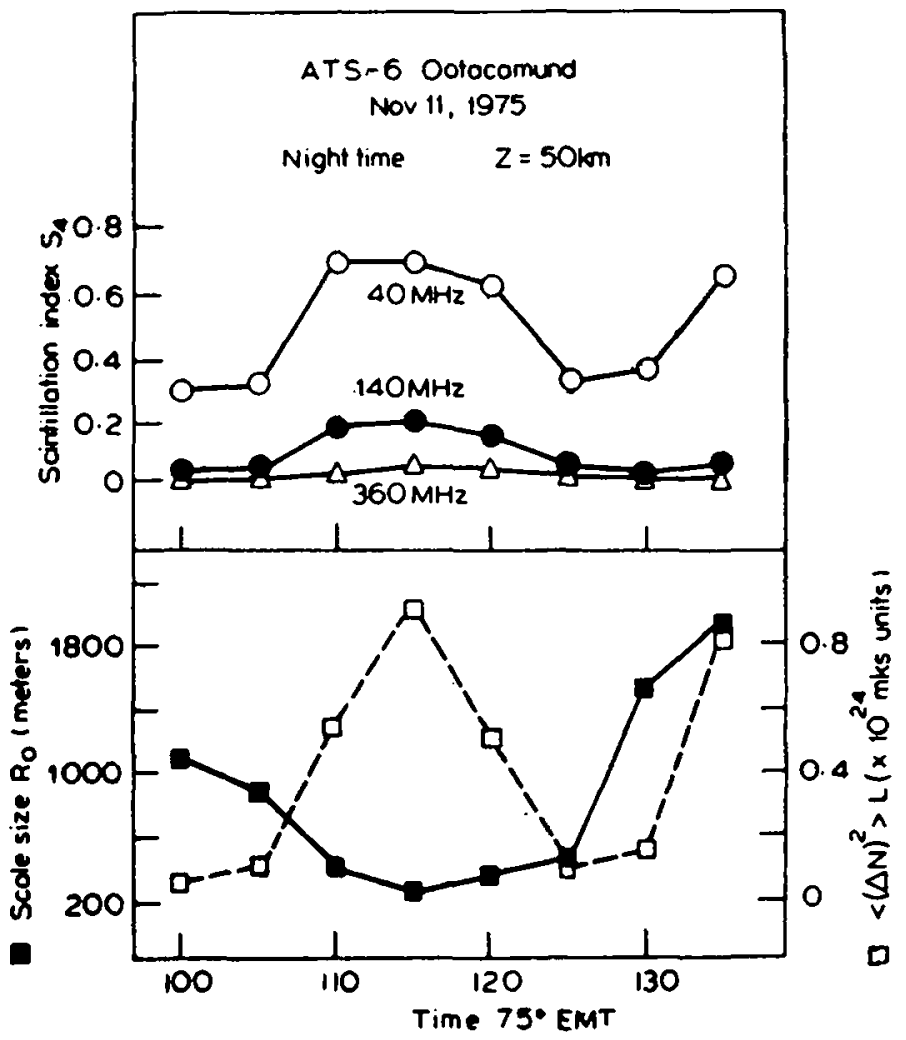

Figure 3. Another nighttime example similar to figure 2 showing filtering effect. 
Farley et al (1970) reported the thickness of spread-F at times to be several hundred $\mathrm{km}$; but the cases we use in this paper are not of very strong spread- $F$. Here the spread thickness can probably be assumed around $30 \mathrm{~km}$. The growth rates for both these cases (having assumed $L=30 \mathrm{~km}$ ) are (1) $6 \times 10^{5} \mathrm{el} / \mathrm{m}^{3} / \mathrm{sec}$ and $5 \times 10^{8} \mathrm{el} / \mathrm{m}^{3} / \mathrm{sec}$, (2) $7 \times 10^{6} \mathrm{el} / \mathrm{m}^{3} / \mathrm{sec}$ and $5.2 \times 10^{6} \mathrm{el} / \mathrm{m}^{3} / \mathrm{sec}$, (3) $7.4 \times$ $10^{6} \mathrm{el} / \mathrm{m}^{3} / \mathrm{sec}$ and $5.6 \times 10^{6} \mathrm{el} / \mathrm{m}^{3} / \mathrm{sec}$ respectively for $a=10,20$ and 30 . For $L=100 \mathrm{~km}$ the respective growth rates worked out range from $3 \times 10^{6} \mathrm{el} / \mathrm{m}^{3} / \mathrm{sec}$ to $4 \times 10^{6} \mathrm{el} / \mathrm{m}^{3} / \mathrm{sec}$. This indicates that these values have reduced by a factor of about half, for an increase of $L$ value by a factor of three and half. These values of growth rate are smaller than those obtained for daytime case.

\section{Conclusions}

Based on simple diffraction theory it is possible to get an estimate of some of the important physical parameters of the ionosphere. These estimates are made using the scintillation observations at multi-frequencies in VHF and UHF bands. It is to be noted that diffraction theory is applicable for weak to moderate scintillation levels. The observations reported in this paper are such that at 140 and $360 \mathrm{MHz}$ the scintillation always remains in the weak scattering limit and it is only at $40 \mathrm{MHz}$ for some cases it reaches to the limit of strong scattering. In spite of this, the ratio of $S_{4}$ values in these observations at 40,140 and $360 \mathrm{MHz}$ can be explained in terms of diffraction approach quite well. Since we consider the ratio of $S_{4}$ values. at two different frequencies in our calculations the errors due to one of them just reaching to a limit of strong scattering will be quite insignificant. However, the observations of ATS -6 at Ootacamund (Deshpande et al 1978) do show severe scintillation cases for which multiple scattering theory needs to be applied, and these are under consideration.

The physical parameters derived from scintillation observations, viz, scale size strength, and growth and decay rates of irregularities are useful in characterising the ionosphere as well as in constructing electrojet models. It is worthwhile to note that the above physical parameters represent an integration over various altitudes. Any altitude-resolution will need in situ measurements which severely restricts the number of measurements that one can make. The results presented here suggest a mechanism in which initially irregularities are generated at large ssale size and which later break-up into smaller and smaller irregularities; during. decay of the irregularities the process is reversed. This seems to be valid for both $E$ and $F$ region irregularities in the ionosphere. As the conditions in the $E$ and $F$ regions are different, the generation mechanism of the irregularities need not be the same, even though the present analysis indicates the similarity between the temporal variations of the scale size and the irregularity strength of the daytime ( $E$-region) irregularities and nighttime ( $F$-region) irregularities. Growth time of the irregularities causing VHF/UHF wave scintillation is about $20 \mathrm{~min}$ (based on simpliffed assumption $e$-fold time of $\triangle N$ ) which agrees with theoretical calculations (Jain 1977) for the F-region. Dyson et al (1974) and Kelley et al (1976) reported that the irregularities are produced over the measured range of scale sizes $(70 \mathrm{~m}$ to $7 \mathrm{~km})$. Our results for day and nighttime irregularities conform with their results. Even though the values of axial ratio and height and thickness 
of the irregular region assumed in the calculations are quite realistic, it should be borne in mind that any temporal variation in these values has not been taken into consideration. This is a limitation of this approach.

\section{Acknowledgements}

Grateful thanks are due to Profs K R Ramanathan, D Lal, S P Pandya and R G Rastogi for the encouragement during the course of this work. ATS-6 Ootacamund project was a joint undertaking of PRL and NOAA and we wish to thank Prof. K Davies for collaboration and Prof. G Swarup for facilities at Ootacamund. Sincere thanks are also due to Dr K S Rao for numerical analysis and Miss Chhaya Shah for computational work. Research at PRL is supported by Department of Space, Government of India.

\section{References}

Aarons J and Whitney H E 1968 Planet Space Sci. 1621

Bowles K L, Balsley B B and Cohen Robert 1963 J. Geophys. Res. 682485

Briggs B H and Parkin I A 1963 J. Atmos. Terr. Phys. 25339

Chandra H, Misra R K, Deshpande M R and Rastogi R G 1970 Indian J. Rad. Space Phys. 8548

Chandra H and Rastogi R G 1974 Curr. Sci. 43567

Chandra H, Vats H O, Deshpande M R, Rastogi R G, Sethia G, Sastri J H and Murthy B S 1979 Ann. Geophys. (in press)

Deshpande M R, Rastogi R G, Vats Hari Om, and Davies K 1978 Proc. Indian Acad. Sci. (Earth Planet. Sci.) A87 173

Deshpande M R, Vats Hari Om and Chandra H 1978 Curr. Sci. 47716

Dyson P L, McClure J P and Hanson W B 1974 J. Geophys. Res. 791497

Farley D T, Balsley B B, Woodman R F and McClure J P 1970 J. Geophys. Res. 757199

Jain R K 1977 Indian J. Rad. Space Phys. 6223

Kelley M C, Haerendel C, Kappler H, Valenzuela A, Balsley B B, Carter D A, Ecklund W L, Carlson C W, Hausler B and Torbert R 1976 Geophys. Res. Lett. 3448

Kent G S and Koster J R 1966 Ann. Geophys. 22405

Köster J R 1972 Planet. Space Sci. 201999

McClure J P 1964 J. Geophys. Res. 692774

Mullen J P 1973 J. Atmos. Terr. Phys. 351187

Prakash S, Gupta S P and Subbaraya B H 1971 Nature (London) 23170

Prakash S, Gupta S P, Sinha H S S and Rao T 1976 Space Res. 16401

Rastogi R G and Iyer K N 1976 Curr. Sci. 45685

Rastogi R G, Deshpande M R and Sen A 1975 Geophys. Res. Lett. 2496

Rastogi R G, Deshpande M R, Vats Hari Om, Davies K, Grubb R N and Jones J E 1977 Pramäna 81 